\title{
PENENTUAN MODEL TERBAIK PADA REGRESI SPLINE MENGGUNAKAN GENERALIZED CROSS VALIDATION (GCV)
}

\author{
Susnawati, Dadan Kusnandar, Yundari
}

\begin{abstract}
INTISARI
Regresi nonparametrik merupakan suatu metode statistika yang digunakan untuk mengetahui hubungan antara variabel respon dengan variabel prediktor jika tidak diketahui bentuk kurva regresinya atau tidak terdapat informasi yang lengkap tentang bentuk pola datanya. Pada penelitian ini, digunakan regresi nonparametrik Spline yang bersifat fleksibel dalam mengatasi pola data yang mengalami kenaikan atau penurunan data dengan bantuan titik knot. Diperlukan beberapa langkah dalam menentukan model regresi Spline terbaik yaitu membuat statistik deskriptif dan matriks plot. Penentuan nilai GCV untuk masing-masing Spline linier, kuadratik, dan kubik dengan satu titik knot. Kemudian dilakukan pengujian asumsi residual. Setelah diperoleh nilai GCV yang paling minimum dan memenuhi asumsi residual, selanjutnya memodelkan persentase penduduk miskin dengan angka melek huruf menggunakan regresi Spline. Studi kasus yang digunakan ialah data persentase penduduk miskin sebagai variabel respon dan angka melek huruf sebagai variabel prediktor. Hasil analisis menunjukkan model regresi nonparametrik Spline linier dengan satu titik knot yang memiliki nilai GCV yang paling minimum. Nilai GCV yang diperoleh adalah sebesar 7,616 dengan titik knotnya adalah 88,35.
\end{abstract}

Kata Kunci: Regresi Nonparametrik Spline, GCV, Titik Knot.

\section{PENDAHULUAN}

Analisis regresi merupakan studi ketergantungan variabel $y$ (variabel respon) terhadap satu atau lebih variabel $x$ (variabel prediktor), yang bertujuan untuk memprediksi (menduga) nilai $y$ jika nilai $x$ diketahui [1]. Hubungan antara variabel $y$ dan $x$ dapat dinyatakan dalam Persamaan (1) berikut ini:

$$
y_{i}=f\left(x_{i}\right)+\varepsilon_{i} \quad ; i=1,2, \cdots, n
$$

dengan, $y_{i}$ merupakan variabel respon, $x_{i}$ merupakan variabel prediktor, $f\left(x_{i}\right)$ merupakan fungsi regresi, dan $\varepsilon_{i}$ merupakan galat dengan asumsi independen memiliki rataan nol dan variansi $\sigma^{2}$.

Terdapat dua pendekatan untuk memprediksi fungsi regresi yaitu pendekatan regresi parametrik dan pendekatan regresi nonparametrik. Pendekatan regresi parametrik mengasumsikan bentuk fungsi regresi atau kurva regresinya yang sudah ditentukan atau diketahui. Pendekatan regresi nonparametrik adalah suatu metode estimasi model yang tidak terikat asumsi bentuk fungsi regresi atau kurva regresi tertentu, karena sebelumnya tidak ada asumsi mengenai bentuk fungsi regresi atau kurva regresinya. Ada beberapa model regresi nonparametrik yang dapat digunakan yaitu Spline, Deret Fourier, dan Kernel [2]. Diantara model-model regresi nonparametrik tersebut, Spline merupakan regresi yang bersifat fleksibel dalam mengatasi pola data yang mengalami kenaikan atau penurunan data dengan bantuan titik knot [2].

Regresi Spline merupakan regresi nonparametrik yang menekankan pada analisis data dengan tetap memperhitungkan kemulusan kurva. Spline merupakan model polinomial yang tersegmen atau terbagi pada suatu titik fokus yang disebut titik knot. Sifat tersegmen atau terbagi inilah yang memberikan fleksibilitas yang lebih baik daripada model polinomial biasa [2]. Ada beberapa kriteria yang harus diperhatikan dalam membentuk model regresi Spline, yaitu menentukan orde untuk model, banyaknya knot, dan lokasi penempatan knot. Model regresi Spline berdasarkan ordenya terdiri dari orde satu (linier), dua (kuadratik), tiga (kubik) sampai orde ke- $m$. 
Pemilihan knot optimal yang dikenal yaitu fungsi resiko prediksi (P), Cross Validation (CV), dan Generalized Cross Validation (GCV). GCV merupakan salah satu pemilihan titik knot yang paling sering digunakan dalam penentuan model regresi terbaik dan dapat digunakan untuk jenis regresi Spline yang ada dikarenakan mempunyai perhitungan yang lebih sederhana [2]. Berdasarkan latar belakang yang telah diuraikan, penelitian ini membahas lebih dalam tentang bagaimana menentukan model terbaik pada regresi Spline menggunakan GCV yang diterapkan pada data penduduk miskin.

Langkah awal dalam penelitian ini adalah membuat statistik deskriptif. Selanjutnya membuat matriks plot antara data persentase penduduk miskin $(y)$ dengan angka melek huruf $(x)$. Penentuan nilai GCV dilakukan untuk masing-masing Spline orde satu (linier), dua (kuadratik), dan tiga (kubik) dengan satu titik knot. Kemudian dilakukan pengujian asumsi residual. Setelah diperoleh nilai GCV minimum dan memenuhi asumsi residual, selanjutnya memodelkan persentase penduduk miskin dengan angka melek huruf menggunakan regresi Spline.

\section{REGRESI SPLINE}

Regresi Spline adalah suatu metode yang digunakan untuk mendapatkan estimasi kurva regresi melalui pendekatan data observasi. Metode ini merupakan model polinomial dengan sifat tersegmen atau terbagi yang memberikan fleksibilitas lebih tinggi. Sifat tersebut memungkinkan model regresi Spline dapat disesuaikan dengan karakteristik data. Keunggulan dari model ini adalah model yang dibentuk dapat mempertimbangkan pola data yang mengalami kenaikan atau penurunan dengan bantuan titik knot. Titik knot adalah suatu titik perpaduan bersama yang menjelaskan terjadinya perubahan pola perilaku dari fungsi Spline pada interval-interval yang berbeda [3]. Bentuk umum regresi Spline berorde ke- $m$ adalah sebagai berikut [4]:

$$
y_{i}=\beta_{0}+\sum_{j=1}^{m} \beta_{j} x_{i}^{j}+\sum_{k=1}^{N} \beta_{m+k}\left(x_{i}-K_{k}\right)_{+}^{m}+\varepsilon_{i}, i=1,2, \cdots, n ; k=1,2, \cdots, N ;
$$

dengan,

$$
\left(x_{i}-K_{k}\right)_{+}^{m}=\left\{\begin{array}{ll}
\left(x_{i}-K_{k}\right)^{m} & ; x_{i} \geq K_{k} \\
0 & ; x_{i}<K_{k}
\end{array} .\right.
$$

Notasi $\beta_{0}$ adalah konstanta; $\beta_{j}$ adalah parameter regresi; $y_{i}$ adalah nilai ke- $i$ dari variabel respon; $x_{i}$ adalah nilai ke- $i$ dari variabel prediktor; $m$ merupakan banyaknya orde; dan $N$ merupakan banyaknya titik knot $K_{1}, K_{2}, \cdots, K_{N}\left(a<K_{1}<K_{2}<\cdots<K_{N}<b\right)$ dengan $a$ merupakan nilai minimum dari $x_{i}$ dan $b$ merupakan nilai maksimum dari $x_{i}$.

Jika data pengamatan sebanyak $n$, maka bentuk matriks dari Persamaan (2) dapat ditulis sebagai berikut:

$$
Y=X_{1} \delta_{1}+X_{2} \delta_{2}+\varepsilon
$$

dengan,

$$
\boldsymbol{Y}=\left[\begin{array}{c}
y_{1} \\
y_{2} \\
\vdots \\
y_{n}
\end{array}\right] ; \quad \boldsymbol{X}_{\boldsymbol{I}}=\left[\begin{array}{ccccc}
1 & x_{1} & x_{1}^{2} & \cdots & x_{1}^{m} \\
1 & x_{2} & x_{2}^{2} & \cdots & x_{2}^{m} \\
\vdots & \vdots & \vdots & \ddots & \vdots \\
1 & x_{n} & x_{n}^{2} & \cdots & x_{n}^{m}
\end{array}\right] ; \quad \boldsymbol{\delta}_{\boldsymbol{I}}=\left[\begin{array}{c}
\beta_{0} \\
\beta_{1} \\
\vdots \\
\beta_{m}
\end{array}\right] ;
$$


$\boldsymbol{X}_{2}=\left[\begin{array}{cccc}\left(x_{1}-K_{1}\right)_{+}^{m} & \left(x_{1}-K_{2}\right)_{+}^{m} & \cdots & \left(x_{1}-K_{N}\right)_{+}^{m} \\ \left(x_{2}-K_{1}\right)_{+}^{m} & \left(x_{2}-K_{2}\right)_{+}^{m} & \cdots & \left(x_{2}-K_{N}\right)_{+}^{m} \\ \vdots & \vdots & \ddots & \vdots \\ \left(x_{n}-K_{1}\right)_{+}^{m} & \left(x_{n}-K_{2}\right)_{+}^{m} & \cdots & \left(x_{n}-K_{N}\right)_{+}^{m}\end{array}\right] ; \quad \boldsymbol{\delta}_{2}=\left[\begin{array}{c}\beta_{m+1} \\ \beta_{m+2} \\ \vdots \\ \beta_{m+N}\end{array}\right] ; \quad \boldsymbol{\varepsilon}=\left[\begin{array}{c}\varepsilon_{1} \\ \varepsilon_{2} \\ \vdots \\ \varepsilon_{n}\end{array}\right]$.

Persamaan (3) dapat juga ditulis $\boldsymbol{Y}=\boldsymbol{X}_{K} \boldsymbol{\beta}_{K}+\boldsymbol{\varepsilon}$, dengan $\boldsymbol{X}_{K}=\left[\begin{array}{ll}\boldsymbol{X}_{\boldsymbol{1}} & \boldsymbol{X}_{2}\end{array}\right]$ dan $\boldsymbol{\beta}_{K}=\left[\begin{array}{l}\boldsymbol{\delta}_{\boldsymbol{1}} \\ \boldsymbol{\delta}_{2}\end{array}\right]$.

Persamaan matriks $\boldsymbol{Y}=\boldsymbol{X}_{K} \boldsymbol{\beta}_{K}+\boldsymbol{\varepsilon}$ merupakan persamaan matriks regresi linier yang telah dimodifikasi dengan menambahkan beberapa kolom pada matriks $\boldsymbol{X}_{K}$ dan beberapa baris pada vektor $\boldsymbol{\beta}_{K}$. Estimasi terhadap vektor parameter $\boldsymbol{\beta}$ dilakukan dengan menggunakan metode kuadrat terkecil yaitu $\hat{\boldsymbol{\beta}}=\left(\boldsymbol{X}^{T} \boldsymbol{X}\right)^{-1} \boldsymbol{X}^{T} \boldsymbol{Y}$. Dengan sedikit modifikasi menyesuaikan persamaan regresi Spline dengan titik-titik knot yang diberikan $K=\left\{K_{1}, K_{2}, \cdots, K_{N}\right\}$ maka estimasi vektor parameter $\boldsymbol{\beta}$ menjadi $\hat{\boldsymbol{\beta}}_{K}=\left(\boldsymbol{X}_{K}{ }^{T} \boldsymbol{X}_{K}\right)^{-1} \boldsymbol{X}_{K}{ }^{T} \boldsymbol{Y}$. Fungsi estimator dari $f(x)$ adalah sebagai berikut:

$$
\begin{aligned}
\hat{f}_{K}(x) & =\boldsymbol{X}_{K} \hat{\boldsymbol{\beta}}_{K} \\
& =\boldsymbol{X}_{K}\left(\boldsymbol{X}_{K}^{T} \boldsymbol{X}_{K}\right)^{-1} \boldsymbol{X}_{K}^{T} \boldsymbol{Y} \\
& =\boldsymbol{A}_{K} \boldsymbol{Y}
\end{aligned}
$$

dengan $\boldsymbol{A}_{\boldsymbol{K}}=\boldsymbol{X}_{\boldsymbol{K}}\left(\boldsymbol{X}_{\boldsymbol{K}}{ }^{T} \boldsymbol{X}_{\boldsymbol{K}}\right)^{-1} \boldsymbol{X}_{\boldsymbol{K}}{ }^{T}$, Notasi $\boldsymbol{X}_{K}$ adalah matriks desain berukuran $n \times(m+N+1)$ dari model yang membentuk estimator $\hat{f}_{K}(x)$ dan bergantung pada titik knot.

$$
\boldsymbol{X}_{\boldsymbol{K}}=\left[\begin{array}{ccccccc}
1 & x_{1} & \cdots & x_{1}^{m} & \left(x_{1}-K_{1}\right)_{+}^{m} & \cdots & \left(x_{1}-K_{N}\right)_{+}^{m} \\
1 & x_{2} & \cdots & x_{2}^{m} & \left(x_{2}-K_{1}\right)_{+}^{m} & \cdots & \left(x_{2}-K_{N}\right)_{+}^{m} \\
\vdots & \vdots & \cdots & \vdots & \vdots & \cdots & \vdots \\
1 & x_{n} & \cdots & x_{n}^{m} & \left(x_{n}-K_{1}\right)_{+}^{m} & \cdots & \left(x_{n}-K_{N}\right)_{+}^{m}
\end{array}\right] .
$$

\section{KRITERIA PEMILIHAN MODEL REGRESI SPLINE}

Ada beberapa kriteria yang harus diperhatikan dalam membentuk model regresi spline, yaitu menentukan orde untuk model, banyaknya knot, dan lokasi penempatan knot. Model Spline yang terbaik dengan titik knot optimal didapat dari nilai GCV minimum. Rumus untuk menghitung GCV adalah sebagai berikut [2]:

$$
G C V(K)=\frac{\operatorname{MSE}(K)}{\left[n^{-1} \operatorname{trace}(\boldsymbol{I}-\boldsymbol{A}(\boldsymbol{K}))\right]^{2}}
$$

dengan $n$ adalah banyaknya data; $\boldsymbol{I}$ adalah matriks identitas; trace adalah penjumlahan elemen pada diagonal utama suatu matriks; $K$ adalah banyaknya titik knot; $\mathbf{A}(\mathbf{K})$ adalah matriks dari $\boldsymbol{X}_{K}\left(\boldsymbol{X}_{K}{ }^{T} \boldsymbol{X}_{K}\right)^{-1} \boldsymbol{X}_{K}{ }^{T} ; \operatorname{dan} \operatorname{MSE}(K)=n^{-1} \sum_{i=1}^{n}\left(y_{i}-\hat{f}_{K}(x)\right)^{2}$.

\section{PENGUJIAN ASUMSI RESIDUAL}

Data yang dianalisis dengan menggunakan regresi nonparametrik Spline harus memenuhi tiga asumsi residual, yaitu asumsi residual independen, asumsi residual identik, dan berdistribusi normal.

a. Asumsi Residual Independen

Asumsi residual independen digunakan untuk melihat apakah terjadi korelasi antar residual atau 
tidak. Asumsi residual independen terpenuhi jika tidak terjadi autokorelasi. Salah satu cara untuk melihat apakah terjadi autokorelasi atau tidak yaitu dengan uji Durbin-Watson. Kriteria pengujiannya adalah dengan uji Durbin-Watson. Kriteria pengujiannya adalah $H_{0}$ diterima jika $d_{\text {hitung }}>d U$.

b. Asumsi Residual Identik

Asumsi residual identik digunakan untuk menguji apakah dalam model regresi terjadi ketidaksamaan varians dari residual satu pengamatan ke pengamatan yang lain. Asumsi residual identik terpenuhi jika tidak terjadi heteroskedastisitas. Salah satu cara untuk melihat apakah terjadi heteroskedastisitas atau tidak yaitu dengan uji Glejser. Kriteria pengujiannya adalah $H_{0}$ diterima jika $F_{\text {hitung }}<F_{\text {tabel }}$ dan $P_{\text {value }}>\alpha$.

c. Asumsi Normalitas Residual

Asumsi normalitas residual digunakan untuk melihat apakah residual berdistribusi normal atau tidak. Asumsi normalitas residual terpenuhi jika residualnya berdistribusi normal. Salah satu cara untuk melihat apakah berdistribusi normal atau tidak adalah dengan uji Kolmogorov-Smirnov. Kriteria pengujiannya adalah $H_{0}$ diterima jika $Z_{\text {hitung }}<Z_{\alpha}$ dan $P_{\text {value }}>\alpha$.

\section{HASIL ANALISIS DAN PEMBAHASAN}

Data yang digunakan pada penelitian ini adalah data sekunder. Data ini didapat dari Badan Pusat Statistik (BPS) Kalimantan Barat di 14 Kabupaten/Kota di provinsi Kalimantan Barat dari tahun 20152017. Ukuran data yang digunakan sebanyak 42 yang terdiri dari beberapa variabel, yaitu persentase penduduk miskin $(y)$ dan angka melek huruf $(x)$. Karakteristik persentase penduduk miskin dapat diketahui melalui statistik deskriptif, dengan cara melihat nilai minimum, maksimum, rata-rata, dan variansi dari masing-masing variabel respon $(y)$ dan variabel prediktor $(x)$.

Tabel 1 Statistik Deskriptif

\begin{tabular}{ccccc}
\hline Variabel & Minimum & Maksimum & Rata-rata & Variansi \\
\hline Persentase Penduduk Miskin $(y)$ & 4,51 & 13,51 & 8,20 & 7,76 \\
Angka Melek Huruf $(x)$ & 88,14 & 97,13 & 92,29 & 4,48 \\
\hline
\end{tabular}

Berdasarkan Tabel 1 diketahui bahwa rata-rata persentase penduduk miskin pada tahun 2015-2017 di Kalimantan Barat adalah sebesar 8,20\%, persentase penduduk miskin terendah terjadi di Kabupaten Sanggau pada tahun 2016 yaitu sebesar 4,51\%, dan persentase penduduk miskin tertinggi terjadi di Kabupaten Landak pada tahun 2015 yaitu sebesar 13,51\%. Angka melek huruf terendah terjadi di Kabupaten Melawi pada tahun 2015 yaitu sebesar 88,14\%, dan angka melek huruf tertinggi terjadi di Kota Pontianak pada tahun 2016 yaitu sebesar 97,13\%, dengan angka melek huruf rataratanya adalah sebesar $92,29 \%$.

\section{PEMODELAN REGRESI SPLINE}

Pemilihan model regresi Spline yang terbaik dipilih berdasarkan lokasi dan banyaknya titik knot. Titik knot yang terbaik dapat dilihat berdasarkan kriteria GCV yang paling minimum.

Tabel 2 Nilai GCV dari Model Regresi Spline

\begin{tabular}{ccc}
\hline Model regresi Spline & Satu Titik Knot & GCV \\
\hline Linier & 88,35 & $\mathbf{7 , 6 1 6}$ \\
Kuadratik & 89,19 & 7,757 \\
Kubik & 88,35 & 8,363 \\
\hline
\end{tabular}


Berdasarkan Tabel 2 dapat dilihat bahwa nilai GCV yang paling minimum adalah sebesar 7,616 yang didapat dari model regresi Spline linier dengan satu titik knot sebesar 88,35. Adapun bentuk model regresi Splinenya adalah sebagai berikut:

$$
\begin{aligned}
f(x) & =\beta_{0}+\beta_{1} x^{1}+\beta_{2}\left(x-K_{1}\right)_{+}^{1} \\
& =827,112-9,253 x^{1}+8,878(x-88,35)_{+}^{1}
\end{aligned}
$$

Selanjutnya dilakukan uji asumsi residualnya:

a. Pengujian Asumsi Residual

Pengujian asumsi residual independen dilakukan untuk melihat apakah terjadi korelasi antar residual atau tidak. Salah satu cara untuk melihat apakah terjadi autokorelasi atau tidak yaitu dengan uji Durbin-Watson. Hipotesis yang digunakan adalah sebagai berikut:

$H_{0}: \rho=0$, artinya tidak terjadi autokorelasi.

$H_{1}: \rho \neq 0$, artinya terjadi autokorelasi.

Hasil perhitungan $d_{\text {hitung }}$ yang didapat adalah sebesar 2,38. Batas atas dan batas bawah taraf nyata dengan $\alpha=0,05$ ialah $d U=1,55$ dan $d L=1,45$. Sehingga dapat diambil keputusan terima $H_{0}$, artinya tidak terjadi autokorelasi, asumsi residual independen terpenuhi.

b. Pengujian Asumsi Identik

Pengujian ini dilakukan untuk melihat apakah dalam model regresi terjadi ketidaksamaan varians dari residual satu pengamatan kepengamatan yang lain. Salah satu cara untuk melihat apakah terjadi heteroskedastisitas atau tidak yaitu dengan uji Glejser. Hipotesis yang digunakan adalah sebagai berikut:

$H_{0}: \sigma_{i}^{2}=\sigma^{2} ; i=1,2,3$, artinya tidak terjadi heteroskedastisitas.

$H_{1}: \sigma_{i}^{2} \neq \sigma^{2} ; i=1,2,3$, artinya minimal ada satu variabel prediktor yang terjadi heteroskedastisitas.

Hasil perhitungan $F_{\text {hitung }}$ yang didapat adalah sebesar 3,02. $F_{\text {tabel }}$ taraf nyata dengan $\alpha=0,05$ ialah $F_{\text {tabel }}=F_{\alpha(k-1 ; n-k)}=F_{o, o 5(2,39)}=3,24$. Sehingga dapat diambil keputusan terima $H_{0}$, artinya tidak terjadi heteroskedastisitas, asumsi residual identik terpenuhi.

c. Pengujian Normalitas Residual

Pengujian ini dilakukan untuk melihat apakah residual berdistribusi normal atau tidak. Salah satu cara untuk melihat apakah berdistribusi normal atau tidak adalah dengan uji Kolmogorov-Smirnov. Hipotesis yang digunakan adalah sebagai berikut:

$H_{0}$ : Residual berdistribusi normal

$H_{1}$ : Residual tidak berdistribusi normal.

Hasil perhitungan yang didapat adalah $Z_{\text {hitung }}=0,12$ dan $P_{\text {value }}=0,08 . Z_{\alpha}$ taraf nyata dengan $\alpha=0,05$ ialah $Z_{\alpha}=0,21$. Sehingga dapat diambil keputusan terima $H_{0}$, artinya residual berdistribusi normal, asumsi normalitas residual terpenuhi.

\section{PENUTUP}

Berdasarkan hasil analisis dan pembahasan, maka diperoleh kesimpulan bahwa model regresi Spline terbaik menggunakan GCV pada data persentasi penduduk miskin dan angka melek huruf pada tahun 2015-2017 di 14 Kabupaten/Kota di Kalimantan Barat adalah model regresi Spline linier dengan satu titik knot. Nilai GCV yang diperoleh adalah sebesar 7,616 dengan titik knotnya adalah 88,35. Adapun bentuk model regresi Splinenya adalah sebagai berikut: 


$$
\begin{aligned}
f(x) & =\beta_{0}+\beta_{1} x^{1}+\beta_{2}\left(x-K_{1}\right)_{+}^{1} \\
& =827,112-9,253 x^{1}+8,878(x-88,35)_{+}^{1}
\end{aligned}
$$

Berdasarkan model regresi Spline linier dengan satu titik knot hubungan antara persentase penduduk miskin $(y)$ terhadap angka melek huruf $(x)$ dapat diinterpretasikan sebagai berikut:

$$
\begin{gathered}
f(x)=827,112-9,253 x^{1}+8,878(x-88,35)_{+}^{1} \\
f(x)= \begin{cases}827,112-9,253 x^{1} & ; x<88,35 \\
747,64-0,466 x^{1} & ; x \geq 88,35\end{cases}
\end{gathered}
$$

Berdasarkan model tersebut, dapat diinterpretasikan bahwa apabila angka melek huruf kurang dari 88,35\% maka persentase penduduk miskin akan berkurang sebesar 9,253 jika angka melek huruf bertambah sebesar satu persen. Sedangkan jika angka melek huruf lebih dari 88,35\% maka persentase penduduk miskin akan berkurang sebesar 0,466 jika angka melek huruf bertambah sebesar satu persen. Sehingga dapat disimpulkan bahwa, semakin tinggi angka melek huruf maka persentase penduduk miskin semakin berkurang.

\section{DAFTAR PUSTAKA}

[1] Gujarati DN. Basic Econometrics 4th Edition. New York: McGraw Hill Companies Inc; 2003.

[2] Putra IMB, Srinadi IGAM, Sumarjaya IW. Pemodelan Regresi Spline. E-Journal Matematika. 2015. 4(3),110-114.

[3] Katijaya SS, Suparti, Sudarno. Regresi Spline sebagai Alternatif dalam Pemodelan Kurs Rupiah Terhadap Dolar Amerika Serikat. Jurnal Gaussian. 2013. 2(3):229-238.

[4] Suparti, Santoso R, Prahutama A, Devi AR. Regresi Nonparametrik. Jawa Timur: WADE GROUP; 2018.

\section{SUSNAWATI}

DADAN KUSNANDAR

YUNDARI
: Jurusan Matematika FMIPA UNTAN, Pontianak susnawati67@gmail.com

: Jurusan Matematika FMIPA UNTAN, Pontianak dkusnand@untan.ac.id : Jurusan Matematika FMIPA UNTAN, Pontianak yundari@math.untan.ac.id 